Special issue of the 2nd International Conference on Computational and Experimental Science and Engineering (ICCESEN 2015)

\title{
Neutronic Analysis of LBE-Uranium Spallation Target Accelerator Driven System Loaded with Uranium Dioxide in TRISO Particles
}

\author{
G. BAKIR ${ }^{a}$, S.B. SelÇUKLU ${ }^{b}$, G. GenÇ ${ }^{b}$ AND H. YAPICI ${ }^{b, *}$ \\ ${ }^{a}$ Cumhuriyet Üniversitesi, Enerji Sistemleri Mühendisliği Anabilimdalı, Sivas, Turkey \\ ${ }^{b}$ Erciyes Üniversitesi, Enerji Sistemleri Mühendisliği Bölümü, Kayseri, Turkey
}

\begin{abstract}
This study presents the neutronic performances of fissile breeding and energy production of a gas cooled accelerator-driven system with LBE-uranium dioxide $\left(\mathrm{UO}_{2}\right)$ spallation target. The accelerator-driven system is designed and optimized by considering various target materials, in terms of neutronic. Two different materials, $\mathrm{LBE}+$ natural $\mathrm{UO}_{2}$ and $\mathrm{LBE}+15 \%$ enrichment $\mathrm{UO}_{2}$ are selected as target materials. The target zone is divided into two parts, one within the other; the outer part is pure LBE target part, and the inner part is $\mathrm{UO}_{2}$ target part cooled with the helium gas. Tristructural-isotropic (TRISO)-coated fuel particles, containing $\mathrm{UO}_{2}$ fuel, are embedded in a carbon matrix pebble with the packing fraction of a $29 \%$, and the pebbles are placed in the $\mathrm{UO}_{2}$ target part and in the fuel core with the packing fraction of a $60 \%$. The fuel core is cooled with helium that is a high-temperature coolant. The target is bombarded with the continuous beams of a $1 \mathrm{GeV}$ protons to produce high-flux neutrons that enter the fuel core. The fuel core is surrounded with a graphite reflector zone serving as both effective moderation and reflection of these neutrons. Furthermore, the whole system is enclosed by boron carbide, $\mathrm{B}_{4} \mathrm{C}$ (shielding zone), to prevent the neutrons leakage out of the accelerator-driven system. The highenergy Monte Carlo code MCNPX along with the LA150 library is used for neutronic calculations. The numerical results bring out that the investigated accelerator-driven system has a high neutronic performance, from the energy production and fissile breeding points of view. Namely, it can be obtained over the thermal power of a $350 \mathrm{MW}$ and produced over the fissile breeding of a $300 \mathrm{~g} /$ day.
\end{abstract}

DOI: 10.12693/APhysPolA.130.30

PACS/topics: 28.20.-v, 28.20.Np, 28.65.+a, 29.20.dg, 29.85.Fj

\section{Introduction}

In an accelerator-driven system (ADS) containing high energetic proton accelerator, spallation neutron target (SNT), and sub-critical core, the main process is the transmutation of nuclear fuels by using proton source having high energy. The target is irradiated by high energetic protons to produce few tens of high energetic neutrons, instantly after, these neutrons diffuse through the sub-critical core including nuclear fuel or wastes. The nuclear wastes are mainly transmuted by means of neutron capture and fission reactions.

Recently, various studies on transmutation of nuclear waste have been investigated in the ADSs. Abanades and Perez-Navarro [1] have worked on the nuclear waste transmutation in a gas cooled ADS loaded fuel pebbles including TRISO fuel particles. The transmutation of minor actinides (MAs) has been investigated in a leadbismuth cooled ADS by Takizuka et al. [2] and Tsujimoto et al. [3]. Moreover, the real pebble numbers fitting the core of a cylindrical ADS has been comprehensively analysed by García et al. [4]. Malyshkin et al. [5] have considered uranium and americium spallation targets and modelled them with Monte Carlo. Martínez et al. [6] have researched neutronic characteristics of accelerator-

\footnotetext{
* corresponding author; e-mail: yapici@erciyes.edu.tr
}

driven systems transmuting nuclear waste. Ismailov et al. [7] have worked on accelerator-driven system with uranium spallation target. In this work, the MAs have been considered as fuel. Yapıcı et al. [8] and [9] have studied on the neutronic data of various infinite target medium irradiated by a proton source and on the nuclear waste transmutation in an ADS, respectively.

\section{Computational model of the considered ADS}

In this work, a conceptual semispherical acceleratordriven subcritical system (see Fig. 1 and Table I) is analyzed for energy production and fissile breeding from uranium dioxide $\left(\mathrm{UO}_{2}\right)$.

TABLE I

Isotopic fractions and densities of the materials used in the investigated ADS.

\begin{tabular}{c|c|c|c}
\hline \hline Material & Density $\left[\mathrm{g} / \mathrm{cm}^{3}\right]$ & Nuclide & Fraction [\%] \\
\hline \multirow{2}{*}{$\mathrm{LBE}$} & 11.344 & $\mathrm{~Pb}$ & 44.5 \\
& 9.8 & $\mathrm{Bi}$ & 55.5 \\
\hline $\mathrm{He}$ & 0.1786 & $\mathrm{He}$ & 100 \\
\hline \multirow{2}{*}{$\mathrm{UO}_{2}$} & \multirow{2}{*}{10.54} & ${ }^{235} \mathrm{U}$ & $0.7-26$ \\
& & ${ }^{238} \mathrm{U}$ & $99.3-74$ \\
\hline Graphite & 2.10 & ${ }^{12} \mathrm{C}$ & 100 \\
\hline \multirow{2}{*}{$\mathrm{B}_{4} \mathrm{C}$} & \multirow{2}{*}{2.52} & ${ }^{10} \mathrm{~B}$ & 18.431 \\
& & ${ }^{11} \mathrm{~B}$ & 81.569
\end{tabular}




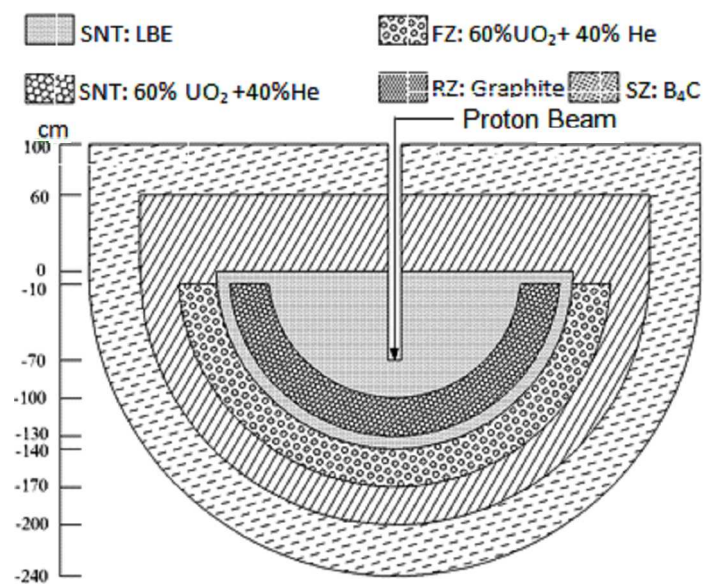

Fig. 1. Cross-sectional view of the ADS (SNT - spallation neutron target, FZ - fuel zone, RZ - reflector zone, SZ - shielding zone).

The $\mathrm{UO}_{2}$ fuels prepared in the form of tristructuralisotropic (TRISO)-coated microspherical fuel particles are buried in carbon matrix pebbles with the TRISO packing fraction $\mathrm{PF}_{\mathrm{t}}=29 \%$ and the pebble packing fraction $\mathrm{PF}_{\mathrm{p}}=60 \%$. TRISO particles are formed as fuel kernel in the center, coated with four layers made of three isotropic materials, (1) porous carbon buffer, (2) inner pyrolytic carbon (IPyC), (3) silicon carbide ( $\mathrm{SiC}$ ) and (4) outer pyrolytic (OPyC) [10]. As is apparent from Fig. 1, there are four different zones: (i) spallation neutron target (SNT), (ii) fuel zone (FZ), (iii) reflector zone (RZ), and (iv) shielding zone (SZ). The target zone is divided into two nested zones: (i) the outer zone is pure LBE target part, and (i) the inner zone is $\mathrm{UO}_{2}$ (either natural uranium, CASE 1 or $15 \%$ enrichment uranium, CASE 2) cooled with the helium gas $\left(\mathrm{VF}_{\mathrm{c}}=40 \%\right)$. Fuel zone known as also subcritical core contains the $\mathrm{UO}_{2}$ fuel to breed fissile fuel and is cooled with high-temperature helium, $\left(\mathrm{VF}_{\mathrm{c}}=40 \%\right)$. The enrichment of uranium in this zone for both target cases is considered in the range of $5 \%-26 \%$. Furthermore, graphite reflector and boron carbide $\left(\mathrm{B}_{4} \mathrm{C}\right)$ shielding zones enclose this $\mathrm{FZ}$ to reflect and absorb the neutrons escaping from the FZ, respectively.

\subsection{Numerical results}

The neutronic data have been obtained by using the high-energy Monte Carlo code MCNPX 2.7 [11] along with the LA150 library [12]. The library consists of evaluated reaction cross-sections and emission spectra up to $150 \mathrm{MeV}$ for incident neutrons and protons, for over 40 target isotopes important in the SNTs, structural materials, and shielding [8]. Bertini INC model [13] is used for the intranuclear cascade of spallation reactions. For the optimum gain $(G)$, proton energy $\left(E_{\mathrm{p}}\right)$ is supposed as $1 \mathrm{GeV}[8,9]$.

\subsubsection{Neutron multiplication and energy gain}

The effective neutron multiplication factor $\left(k_{\text {eff }}\right)$ is the ratio of one generation of neutrons to the next generation. The energy gain, $G$, is the ratio of the total energy production to the energy of the proton beam. Its value can be calculated as follows:

$$
G=\frac{R_{\mathrm{f}} E_{\mathrm{f}}}{E_{\mathrm{p}}}
$$

where $R_{\mathrm{f}}$ is the number of fission reaction and $E_{\mathrm{f}}$ is the energy per fission (200 MeV).

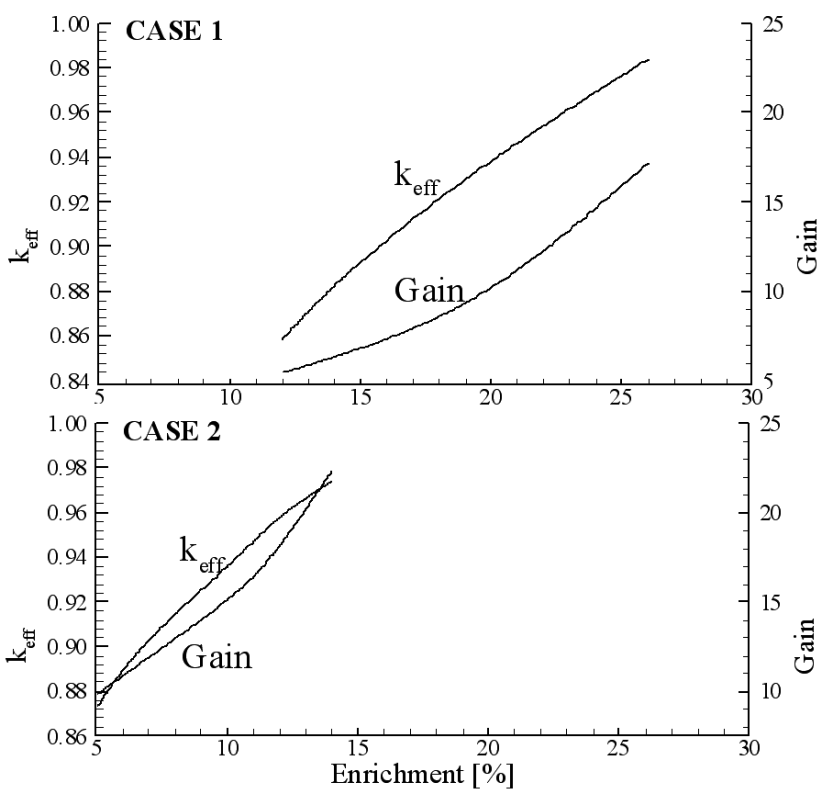

Fig. 2. Variations of the energy gain and the effective neutron multiplication factor depending on the enrichment of uranium in the FZ.

Figure 2 shows the variations of $G$ and $k_{\text {eff }}$ in the target CASEs 1 and 2, depending on the enrichment of uranium. In this research, the fuel enrichments are determined that $k_{\text {eff }}$ is ensured in the range of 0.86 to 0.98 . According to these values, the values of $G$ vary in the range of 5 to 23, depending on target case and the enrichment of uranium. The gain reaches higher values with lower enrichment in the target CASE 2 with respect to the target CASE 1. Their values are also seen in Table II.

TABLE II

Neutronic data in the case of $k_{\text {eff }}=0.98$ for $\mathrm{PF}=10^{17}$ protons/s which corresponds to 16.02 MW.

\begin{tabular}{c|c|c|c|c|c|c}
\hline \hline SNT & Enrichment & & $P_{\text {th }}$ & \multicolumn{3}{|c}{ Fissile fuel breeding $[\mathrm{g} /$ day $]$} \\
\cline { 5 - 7 } CASE & {$[\%]$} & $\mathrm{G}$ & {$[\mathrm{MW}]$} & ${ }^{239} \mathrm{Pu}(\mathrm{SNT})$ & ${ }^{239} \mathrm{Pu}(\mathrm{TZ})$ & Total \\
\hline 1 & 26 & 17 & 276 & 110 & 120 & 230 \\
2 & 15 & 23 & 376 & 139 & 176 & 315
\end{tabular}

\subsubsection{Densities of fissile breeding and fission}

Both energy production and fissile breeding are priority matters in ADSs. In this study, major fissile breeding reaction is:

$$
{ }^{238} \mathrm{U}(\mathrm{n}, \gamma){ }^{239} \mathrm{U} \stackrel{\beta}{\longrightarrow}{ }^{239} \mathrm{~Np} \stackrel{\beta}{\longrightarrow}{ }^{239} \mathrm{Pu} .
$$

Figure 3 depicts the variations of capture reaction densities $\left(\mathrm{R}_{\gamma} \mathrm{D}\right)$ of ${ }^{238} \mathrm{U}$, which equal to ${ }^{239} \mathrm{Pu}$ fissile breeding 
densities (see Eq. (2)), in SNT and FZ for both target cases, depending on the enrichment of uranium in the FZ. As is apparent from this figure, more fissile fuel $\left({ }^{239} \mathrm{Pu}\right)$ is produced in SNT (inner target zone) with respect to the FZ. Furthermore, for proton flux, $\mathrm{PF}=10^{17}$, having energy of a $1 \mathrm{GeV}$, productions of $239 \mathrm{in} \mathrm{g} /$ day are given in Table II. The values of total ${ }^{239} \mathrm{Pu}$ breeding in the target CASEs 1 and 2 are 230 and $315 \mathrm{~g}$ /day, respectively.

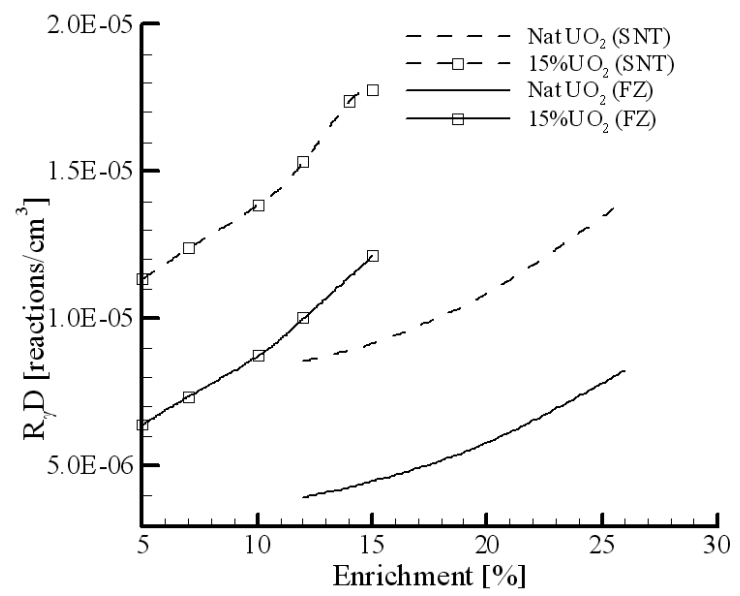

Fig. 3. Variations of ${ }^{239} \mathrm{Pu}$ breeding density in the both CASEs 1 and 2 depending on the enrichment of uranium in the FZ.

The fission reaction densities $\left(\mathrm{R}_{\mathrm{f}} \mathrm{D}\right)$ in the SNT and in the FZ are plotted in Fig. 4 versus the uranium enrichment for both target cases. As is apparent from this figure, more fission reaction occurs in the enrichment uranium cases that this is an expected situation. For proton flux, $\mathrm{PF}=10^{17}$, having energy of a $1 \mathrm{GeV}$, thermal power ( $P_{\mathrm{th}}$ in $\left.\mathrm{MW}\right)$ being proportional to fission reaction is in the range of 276 to $377 \mathrm{MW}$ (see Table II).

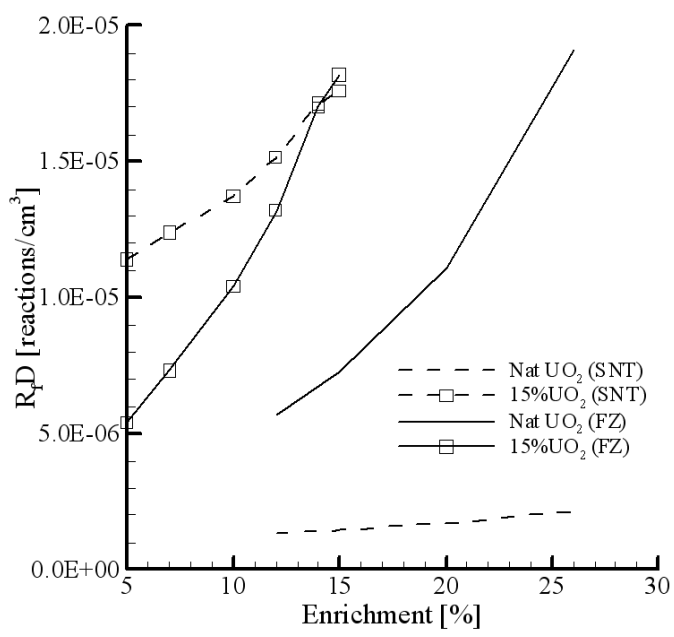

Fig. 4. Variations of fission density in the both CASEs 1 and 2, depending on the enrichment of uranium in the $\mathrm{FZ}$.

\section{Conclusion}

For fissile fuel breeding and energy production, a conceptual semispherical ADS has been designed and analyzed. The main numerical results derived from this analysis are given briefly as follows:

- From neutronic performance the point of view, the $\mathrm{LBE}+15 \%$ enrichment $\mathrm{UO}_{2}$ target is the best case.

- Appreciable amount of ${ }^{239} \mathrm{Pu}$ can be bred from ${ }^{238} \mathrm{U}$ fertile fuel in all considered cases.

- Total production of ${ }^{239} \mathrm{Pu}$ reaches up to $315 \mathrm{~g}$ per day.

- The energy gain can reach up to 23 . It indicates that this value is a remarkable energy multiplication.

- The thermal power of a $377 \mathrm{MW}$ can be produced.

Consequently, this conceptually designed ADS has a good neutronic performance in terms of energy production and fissile fuel breeding.

\section{Acknowledgments}

This study is supported by the Research Fund of the Erciyes University, project no. FDK-2015-5811.

\section{References}

[1] A. Abanades, A. Perez-Navarro, Nucl. Eng. Design. 237, 325 (2007).

[2] T. Takizuka, K. Tsujimoto, T. Sasa, K. Nishihara, H. Takano, Prog. Nucl. En. 40, 505 (2002).

[3] K. Tsujimoto, T. Sasa, K. Nishihara, H. Oigawa, H. Takano, J. Nucl. Sci. Technol. 41, 21 (2004).

[4] L. García, J. Pérez, C. García, A. Escrivá, J. Rosales, A. Abánades, Nucl. Eng. Des. 253, 142 (2012).

[5] Y. Malyshkin, I. Pshenichnov, I. Mishustin, W. Greiner, Nucl. Instrum. Methods Phys. Res. B 334, 8 (2014).

[6] A.H. Martínez, Y. Kadi, G. Parks, Ann. Nucl. En. 34, 550 (2007).

[7] K. Ismailov, M. Saito, H. Sagara, K. Nishihara, Prog. Nucl. En. 53, 925 (2011).

[8] H. Yapıcı, G. Genç, N. Demir, Ann. Nucl. En. 34, 374 (2007).

[9] H. Yapıcı, G. Genc, N. Demir, Ann. Nucl. En. 35, 1264 (2008).

[10] H.C. Kim, S.Y. Kim, J.K. Kim, J.M. Noh, in: 13th Int. Conf. on Emerging Nuclear Energy Systems, Istanbul (Turkey), 2007.

[11] D.B. Pelowitz, MCNPX, User's Manual, Version 2.6.0, LA-CP-07-1473, 2008.

[12] M.B. Chadwick, P.G. Young, S. Chiba, S.C. Frankle, G.M. Hale, H.G. Hughes, A.J. Koning, R.C. Little, R.E. MacFarlane, R.E. Prael, L.S. Waters, Nucl. Sci. Eng. 131, 293 (1999).

[13] H.W. Bertini, Phys. Rev. 188, 1711 (1969). 